\title{
The Influence of Social Presence in Online Classes Using Virtual Conferencing: Relationships between Group Cohesion, Group Efficacy, and Academic Performance
}

\author{
Pilhyoun Yoon ${ }^{1, * \mathbb{D}}$ and Junghoon Leem ${ }^{2}$ \\ 1 Department of Secretary, Inha Technical College, Incheon 22212, Korea \\ 2 Department of Creative Human Resource Development, Incheon National University, Incheon 22012, Korea; \\ jhleem@inu.ac.kr \\ * Correspondence: yph333@naver.com or yoonph@inhatc.ac.kr
}

Citation: Yoon, P.; Leem, J. The Influence of Social Presence in Online Classes Using Virtual Conferencing: Relationships between Group Cohesion, Group Efficacy, and Academic Performance. Sustainability 2021, 13, 1988. https://doi.org/ $10.3390 /$ su13041988

Academic Editor: Marc Alier

Received: 17 January 2021

Accepted: 8 February 2021

Published: 12 February 2021

Publisher's Note: MDPI stays neutral with regard to jurisdictional claims in published maps and institutional affiliations.

Copyright: (c) 2021 by the authors. Licensee MDPI, Basel, Switzerland. This article is an open access article distributed under the terms and conditions of the Creative Commons Attribution (CC BY) license (https:// creativecommons.org/licenses/by/ $4.0 /)$.

\begin{abstract}
One of the important issues that computer-supported cooperative work (CSCW) and human-computer interaction (HCI) researchers want to solve through cooperative system design is the improvement of performance. The same is true for virtual learning environments. The role and importance of technology in education have increased due to the COVID-19 pandemic, while the need to explore factors that influence social and academic efficacy in virtual environments has increased based on the explosion in online virtual teaching environments and virtual conference apps. Based on the theoretical description of group cohesion for the purpose of enhancing further collaboration, this paper asks what role group cohesion plays and how significant it is to group efficacy and performance in virtual learning environments, and also whether a sense of social presence in a virtual learning environment plays a significant role in optimizing group cohesion and, thus, group performance. Experimental studies were conducted on a total of 121 people consisting of 35 virtual learning groups. Results show that a sense of social presence has a positive effect on group efficacy, and that the adjustment effect of social presence has significant positive effects on group cohesion and group efficacy. This study provides a theoretical and empirical basis for the design of methods that can maximize positive effects in support of group learning and collaboration in virtual learning environments.
\end{abstract}

Keywords: social presence; group cohesion; group efficacy; academic performance; virtual conferencing

\section{Introduction}

Researchers in computer-supported cooperative work (CSCW) and human-computer interaction (HCI) communities have become interested in designing cooperation, collaboration, and interaction methods for e-learning because the cognitive development of students varies with the degree of social interaction they are exposed to [1-6]. However, e-learning still presents limitations in interactions between teachers and students and between participating students $[7,8]$. It is quite difficult to pursue active (in-person educational) interaction between e-learning teachers and students where learning content is primarily delivered unilaterally and while face-to-face encounters between teachers and students are limited. These problems are greatly exacerbated during a pandemic in which face-to-face interaction is specifically avoided $[9,10]$. COVID-19 social distancing regulations make it very difficult to exploit the beneficial effects and enhancements of social presence, which now need to be compensated for through improved e-learning methods and environments. E-learning environments also impose special interaction difficulties between learners in cooperative and collaborative projects [11,12]. In collaborative learning, the forming of groups among student participants can reduce anxiety, encourage symbiotic efficacy, stimulate and hasten critical thinking processes, and enhance relational power. Some studies show that these effects are especially beneficial to improving the performance of students with below av- 
erage grades [13-15]. However, to achieve these effects, questions remain as to how best to conduct collaborative learning and derive the benefits of a sense of social presence in e-learning environments [16]. Most teachers and learners are more familiar with traditional offline in-person styles of social interaction, and may have difficulty transitioning to collaborative e-learning and finding ways to approach, enhance, and maximize e-learning opportunities [17].

In the summary, we list issues of concern in e-learning environments, which have suddenly replaced in-person classes due to the COVID-19 pandemic. The first is unfamiliarity and difficulty offering learning guidance in non-face-to-face situations. Second, teaching and interaction styles are restricted due to increased instructional unilateralism and interaction limitations. Third, difficulties operating technology-mediated collaborative learning systems stand in contrast with traditional in-person interaction between learners and teachers.

On the other hand, the importance and contingent value of supporting online meetings in e-learning since COVID-19 has been emphasized $[18,19]$. In particular, virtual environments (VE) such as virtual conferencing (VC) applications can provide users with a strong sense of realism and immersion, a kind of interactive digital environment that allows them to mimic offline interactions $[19,20]$. Various kinds of activities such as meetings, education, skill acquisition, and social gatherings can be supported through VC. In VE, a key user experience (UX) factor is a social presence [21,22]. Here, social presence describes the feeling of connectivity in virtual space $[23,24]$; social presence receives a great deal of attention in VE-based cooperative learning $[25,26]$. According to prior research, the degree to which learners understand what they have learned and the ability to generate their own knowledge depend on their sense of social presence [27]. Social presence is therefore considered an important factor for building and participating in cooperative VE learning environments, and is also widely used to evaluate the learner's experience (UX) in virtual learning environments [28]. As the level of social presence perceived by learners in VC learning environments increases, it is expected that social learning activities will be more widely used and that they will make positive contributions to learning performance. For this reason, a VC-based learning environment with a higher level of social presence could help optimize UX and improve learning outcomes.

The main purpose of this study is to understand and promote more effective factors and potential for inter-student collaboration in VC-based learning environments compared to regular unilateral e-learning environments, to propose a more effective VC-based learning design and to propose an approach that can improve learning performance via a stronger sense of social presence. This paper makes the following contributions.

(1) We propose a theoretical model that describes the mechanisms by which group cohesion is achieved along with greater learning outcomes resulting from efficiently facilitated cooperation among students in VC-based learning environments.

(2) We test the importance and efficacy of the sense of social presence and group cohesion and their effects on learning performance in VC environments. Our experimental results show that VC-based learning with strong group cohesion achieves higher levels of group efficacy and learning performance than straight e-learning interactions. Our results also show that, even without face-to-face interactions offline, group participants can experience strong group cohesion and achieve team outcomes and goals via VC.

(3) We propose an approach to strengthen group cohesion and learning performance by identifying, analyzing, and strengthening the sense of social presence in VCbased learning.

\section{Theoretical Background}

\subsection{Group Cohesion}

Ideally, a group is not just a collection of members, but a cohesive whole in which group members bond with each other in interdependence and purpose [29]. This sense of 
solidarity is called 'group cohesion', and is one of the most important experiences in group dynamics. Because studies of groups generally confirm the relationship between cohesion and performance, many people give special consideration to cohesion as a key factor in group success [30,31]. We have identified two important contributing characteristics of a successful cohesive group. First, the success of cohesive groups is partly due to the level of cooperation achieved by such groups. In a cohesive group, each member's contribution is more readily harmonized with those of other members. Cohesion serves as a 'lubricant' that minimizes friction and conflict among members of the group [32,33]. Second, all members of a cohesive group have the same 'mental model' of the group's tasks. A 'shared prescription' on how to successfully complete the task promotes efficient group performance. As a result, when group tasks require frequent interaction and high interdependence between members, groups with strong cohesion are likely to outperform groups lacking a strong sense of cohesion [34].

As the importance of non-face-to-face interaction has grown, the rapid development of VC technology has been hastened by an unprecedented demand for realistic and effective interaction systems $[35,36]$. The development of these technologies is normalizing group participant interactions in virtual spaces by making VC interface environments more accessible and more convenient and natural to use. VC environments that are convenient, easily accessed, and aligned to natural human functioning can facilitate online activities and discussions and, thereby, promote social identity and group cohesion, and such groups can further benefit from comparison and exchanges with the activities of other groups. In other words, intra-group cohesion can make intra-group exchanges more significant and beneficial by allowing the group to move with singularity of mind and purpose and by deriving benefit from similarly accessible associates in other groups. In learning groups under a VC-based classroom environment, group cohesion is formed through social identification and social and input diversity and exchanges of and between members. Such benefits can be expected to impact group performance that reflects the form, character, and level of cohesion achieved by a well-designed interaction environment.

\subsection{Group Efficacy}

Social cognitive theory emphasizes the process of human thought and assumes that people do social learning by observing others [37,38]. However, non-face-to-face environments limit social learning by the direct observation of others because direct observation is generally not available [39]. According to social information processing theory [40], groups formed in non-face-to-face environments are restricted from acquiring social information about their peers because of their limited access to non-verbal communication cues. Compared to groups in face-to-face environments, groups in non-face-to-face environments take more time to communicate and to develop relationships between themselves [40].

Nevertheless, prior studies have shown that with sufficient time, non-face-to-face environments can adapt to their environments and enjoy equally satisfying and productive interaction experiences as those in face-to-face environments [41]. While it takes a great deal of time for social information to accumulate within groups under non-face-to-face situations, social information is shared nevertheless [39].

Social cognitive theory values the self-concept, i.e., how one feels about and perceives oneself. The expectation that one can perform certain actions well in certain situations is called "efficacy expectations". The recognition of one's efficacy expectations is called self-efficacy [42]. Social cognitive theory considers self-efficacy to be a major predictor of human behavior [38,42] and self-efficacy extended to groups is called group efficacy [43]. Group efficacy is defined as "the belief that members share with each other that they can demonstrate any ability or attain achievement goals at the group level" [38]. Prior studies emphasize self-efficacy and group efficacy as correlated yet distinct concepts [44,45]. Each member's assessment of group efficacy is considered to be more important than the effects of the individual members' self-efficacy because group efficacy can be low even 
when individual self-efficacy is high and when peers are perceived to be low in functional efficacy [46].

The dynamics within the learning group in respective educational environments suggest ways to deal with conflicts among group members, the approaches of which effectively encourage all members to participate in the learning process, and demonstrate how to improve the benefits generated from the learning group's particular make-up and experience [39]. However, research is exceedingly rare regarding which factors improve group function in non-face-to-face educational situations and how those factors are created and nurtured. Therefore, through group-level research for group efficacy in VC-based online classroom environments, it is necessary to explore ways to enhance educational efficacy through group functions and to enable group members to learn efficiently together.

\subsection{Social Presence}

Learning communities accumulate knowledge through collaborative learning interaction. Each learner's sense of connection to others online is a most important factor in the learning community's experience and performance. This is described as social presence [47-49]. Social presence is determined to the extent that participants recognize others through interaction and to the extent that they are aware of the resulting (residual) interpersonal relationships that are established via those interactions [50,51]. When these definitions for social presence were first proposed, media such as computers did not provide relevant conditions and were thus assessed as capable of producing only low social presence and appropriate interaction was said to be difficult to achieve. However, the study and understanding of social presence has since changed to the extent that it can also reveal itself in computer-mediated communications [52,53]. Later, Garrison and Anderson [54] defined social presence as the ability of learners to express themselves socially and emotionally in the learning community, deeming this the most fundamental element in forming and maintaining communities in an online learning environment. Feedback narrows the psychological distance between the teacher and the learner in online communications; this leads to learning satisfaction. Garrison and Arbaugh [55] stated that collaborative learning increases social presence in online learning and that this not only increases learner satisfaction and community awareness, but also intensifies the social and emotional atmosphere. On the other hand, studies show that a lack of social skills makes learners feel frustrated, causing them to develop a critical attitude toward the instructor, and thus lowers the level of empathetic learning [56,57].

\section{Hypotheses Development}

Based on the research outlined above, we derived a set of hypotheses that link group cohesion, social presence, group efficacy, and academic performance (see Figure 1).

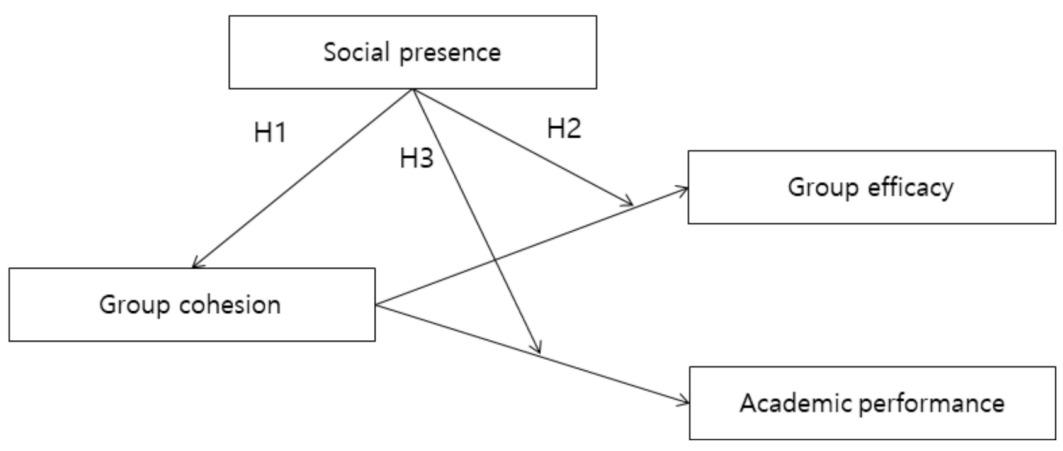

Figure 1. Theoretical model.

\subsection{Social Presence and Group Cohesion}

We argue that the sense of social presence perceived by virtual groups in VC-based learning is related to group efficacy. This is because social presence encourages immediate 
nuanced adjustments in interactions. Preceding studies also discussed the importance of social presence in the online cooperative learning environment. In particular, social presence has been highlighted as an important factor in the process of using computerbased communication systems, such as social media and VC as a tool for social interaction. In VC-based learning, where learners can transmit and receive both screen images and voice messages from interaction participants, the perception that learners are connected to each other may be stronger than with other online media. Rogers and Lea [58] argued that in order to increase social presence in online cooperative learning, it is necessary to raise the participants' awareness of group identity. In addition, the higher the sense of social presence, the higher the participation in online cooperative learning, which will ultimately have a positive impact on academic achievement. These findings provide the basis for discussion on what the social presence of learners may mean and how it can function in an online cooperative learning environment. Thus, in a VE-based learning situation, social presence may be a learning variable that can affect the formation of group cohesion and produce better outcomes.

Hypothesis 1 (H1). Members who recognize a high level of social presence in VC-based learning experience high level group cohesion.

\subsection{Social Presence, Group Cohesion, Group Efficacy, and Academic Performance}

In an online learning environment, group members with common learning goals become aware of the identity of the learning community, and this perception leads to enhanced participation and better learning results via improved group cohesion and mutual affinity for the group and its common values and goals [59].

In addition, group efficacy not only has a positive effect on problem solving and learning promotion through efficient communication among group members, it also has the effect of coordinating and integrating the knowledge and skills of individual group members at the group level [44]. This group efficacy is a decisive factor in improving group performance [60]. On the other hand, according to group affective tone theory, the more positive the group members' perception of the group, the more likely their actions are to be group-friendly [61].

Therefore, when the group pursues high-norm performance based on a positive perception of the group, the performance result of the group with high cohesion is better than that of the group with low cohesion [1,61]. Moreover, a group is a complex social system that influences member behavior in various ways. Therefore, the sum of group member competencies does not necessarily determine the level of performance [43]. Accordingly, previous studies have revealed that the recognition of a positive group identity as a group member is an essential factor to efficiently achieve the group's goal [62]. We emphasize the importance of individual learners having an identity in the learning community, including VC-based learning situations. Identity will appear as a phenomenon of group cohesion, which, in turn, enhances learning attitudes and academic performance. Thus, it is expected that group members who perceive a high level of social presence in a VC-based learning situation will show a higher level of group efficacy and academic performance $[60,63]$. The sense of belonging and human relatedness among learners differs according to their respective level of social presence perception; this is because this sense influences learning motivation and learning outcomes [60]. However, active interaction between learners online does not necessarily mean they feel a sense of social presence. In order to recognize the sense of social presence, the element of "feeling that the individual is there" must be included [27]. Therefore, a VC-based learning situation with enhanced face-to-face interaction can provide a sense of reality beyond that found in existing online learning. Previous studies argue that the higher the perception of social presence, the higher the satisfaction and outcome of individual learning in an online learning environment $[56,64,65]$. However, there are insufficient studies on the moderating effects of social presence for groups com- 
pared to studies of individual social presence. Accordingly, this study established the following research hypothesis focusing on the moderating effect of social presence.

Hypothesis 2 (H2). Group cohesion in a VC-based learning environment has a more positive influence on group efficacy when the perception of social presence among the group members is higher.

Hypothesis 3 (H3). Group cohesion in a VC-based learning environment has a more positive influence on academic performance when the sense of social presence of group members is higher.

\section{Research Methodology}

Very little, if anything, is known about the interplay between social presence and group cohesion and its influence on group efficacy. To address this deficiency, we conducted a lab experiment to examine the effect of social presence and group cohesion on group efficacy and academic performance in a virtual learning environment using a virtual conferencing application.

\subsection{Participants}

All participants are college students. The study was conducted on a total of 125 freshmen that were taking the Management Academy course in a university's secretarial department located in Incheon, Korea; the teacher was from the same university. In this study, 125 students were organized into one class. The participants were all female, and their average age was 21.4 years. In the analysis, 121 copies of questionnaire data were used, and the total number of groups was 35 (average three or four persons in a group).

\subsection{Treatments}

According to previous studies, the experience of face-to-face contact in the offline environment can influence the formation of group cohesion [66]. In this study, it was also determined that the offline face-to-face contact experience could have an effect on the formation of social relationships. Therefore, in this experiment, the main subjects of study were students who did not have offline face-to-face contact experiences. The students who participated in this study were freshmen entering the spring semester of 2020. In other words, all of them are new female college students. Due to the COVID-19 pandemic, they started online classes without any previous face-to-face contact opportunities such as entrance ceremonies and department orientation classes. Freshmen in the same class therefore were largely unfamiliar with each other. Taking advantage of this situation, we were able to organize a small learning group of students with no face-to-face experience whatsoever. The choice of learning group members was achieved via the random selection function found in the Microsoft Excel software. Using Excel led to the creation of a total of fifteen groups of three people and twenty groups of four people.

\subsection{Common Method Bias}

The survey was conducted three times in total from 4 May to 26 June 2020, to solve the common method bias problem. Common method bias occurs when an independent variable and dependent variables are measured in the same time frame, with the same tool, and on the same response source [67]. Therefore, the most strictly controlled aspect in the design of this study was to solve the common method bias issue. In this study, the effect of independent variable group cohesion on the dependent variables group efficacy and on academic performance has a causal relationship between cause (independent) and result (dependent). In this causal model, each variable should be measured at different times to understand their relationship. If these variables had all been measured together at the same time, the correlation between them could have been identified, but it would have been impossible to infer the causal relationship. Thus, the surest way to resolve the problem of common method bias in this study was to vary the measurement methods 
between each variable. First, we separated the response sources. Group cohesion, group efficacy, and social presence variables were obtained from the students' responses, while the academic performance variable was obtained from the students' actual test results. Next, we separated the measurement environment. This method includes time separation, which measures each variable at a time interval, spatial separation, which separates the measurement environment of each variable, and psychological separation by using separate questionnaires, which prevents the variables under consideration from being recognized and related. We aimed to reduce the respondents' motivation for consistency by using time and psychological separation.

\subsection{Task}

In this study, the virtual class was conducted as an online class on the VC app called ZOOM (https:/ / zoom.us). The class was conducted in three steps. First, the teacher sent the class link via social media on time, and the students participated in the class through the link. Second, after the class, the problem-solving activities related to the contents of the class were carried out by each small group. Third, the results of problem-solving activities by small groups were reported to the teacher through social media. A total of 10 real-time classes and small group activities were conducted through this procedure. The small groups took 'business management theory' through an online video conference app once a week. After a two-hour class, the small groups engaged in problem-solving activities for about an hour on ZOOM. Problem-solving activities included both multiple-choice questions to check academic performance and subjective questions that were difficult to solve without activities such as brainstorming (e.g., 'What management strategies can Company A use?'). In particular, solving subjective questions required logical problem-solving activities involving all small group members. Specifically, they performed intellectually challenging tasks, such as spreadsheet data analysis, cost estimation, presentations on the basis for decisions, and opinion-compromising activities to find optimal answers. In addition, the teacher provided feedback on task performance results to allow them to feel the efficacy of the successful execution of difficult tasks. It is important to induce active participation and cooperation in meetings in small group activities based on VC. Thus, this study intentionally chose logical problem-solving activities that individuals could not perform alone without a number of participants. Logical problem-solving questions, which are difficult for individuals to solve alone, encourage geographically dispersed members to gather in virtual spaces. These activities have been identified as a way to rally virtual teams in studies conducted by Poltrock and Engelbeck [68] and Mark [69]. In addition, problem-solving activities that necessitate group participation naturally encourage active interactions among members in virtual space. Active interactions in a virtual space enhance a sense of social presence as if members were in the same space [22,70].

\subsection{Experimental Setting}

Group cohesion is not formed in a short time; it requires the performance of cooperative activities over a relatively long period. In this study, group cohesion was measured after group activities were performed for a total of 30 hours. After group cohesion was measured, group efficacy and social presence were measured through an additional 15 hours of group activity. In the end, we experienced a total of 45 hours of group activity to measure group efficacy and social presence. In addition, the results of each group activity and the final test results were combined to aggregate academic performance. The specifics are as follows: The small groups took ten classes and conducted ten problem-solving activities over ten weeks from 2 March 2020. They were then surveyed for three days from 4 May 2020 to measure the group cohesion variable (stage 1). They continued to take ZOOM classes for two hours once a week and conducted a one-hour problem-solving activity for five weeks from 11 May 2020, and were surveyed for three days from 15 June 2020, to measure the collective efficacy and social presence variables (stage 2). As we judged that group cohesion and group efficacy would have a causal relationship, the timing for 
measuring group cohesion preceded the measuring of group efficacy. Since social presence is a concept that evaluates the entire learning experience, we chose to evaluate it after all the online classes and small group activities were completed. Finally, the results of all academic activities were collected for four days from 22 June 2020, when the final results were aggregated.

\subsection{Dependent Variables}

\subsubsection{Social Presence}

Social presence was defined as the recognition of the formation of bonds between instructors and students, or between students and students, and the development of social relationships. To measure the sense of social presence, a tool developed by Kang et al. [71] was used. This scale is composed of a total of six items, including coexistence and influence, within VC environments. For example, coexistence includes items such as 'the students seem to know of my existence', and influence includes items such as 'the students accept each other's opinions well'. All responses were measured on a 5-point Likert scale; the higher the score, the higher the level of felt social presence.

\subsubsection{Group Cohesion}

Group cohesion is a variable formed at the group level, which Wang et al. [72] defined as a bond that occurs during the group's task. Siebold [73] referred to it as the ability to achieve trust and teamwork through ties formed between members. In this study, group cohesion levels were measured based on four of the elements of cohesion proposed by Forsyth [29]. The four elements of Forsyth's proposal [29] are divided into (1) task cohesion, (2) social cohesion, (3) perceived cohesion, and (4) emotional cohesion. All questions were measured on the 5-point Likert scale; the higher the score, the higher the level of task, social, emotional, and perceived cohesion.

\subsubsection{Group Efficacy}

Group efficacy, another variable formed at the group level, can be understood as a belief shared by the members that they can exercise any ability or achieve goals at the group level [38]. In this study, we used the questionnaire (Appendix A) for measuring group efficacy in the context of group learning activities. For the design of the questionnaire, seven questions, conceived by Lee [63], were used. Lee's study measured group efficacy for public officials in learning clubs with questionnaires that we modified for the purpose of our study. The origin of the measuring tool used by Lee [63] is seven questions of the Collective Efficacy Scale developed by Rigg and Knight [62]. These questions were also measured on the 5-point Likert scale; the higher the score, the higher the group efficacy.

\subsubsection{Academic Performance}

In this study, we utilized the final exam scores (perfect score: 120) for each individual learner as an indicator of individual academic performance, with the average score for each individual learner belonging to the same learning group representing the group's academic performance. The learner must complete the activities designated by the teacher within a set period of time in step with the learning order and time, and the scores given by the teacher for the activities they participated in are summed up to become the total score for the learner. The criteria for scoring the subjects were attendance (20\%), participation in online learning activities $(10 \%)$, quiz activities by group $(20 \%)$, midterm exams $(25 \%)$, and final exams $(25 \%)$.

\subsection{Control Variables}

The students participating in this study were all freshmen that belonged to the same department and took the same course. All were female. Thus, demographic factors have not been introduced as control variables. Furthermore, according to a prior study, the 
number of members in a group could affect the analysis results, and thus group size was added as a control variable.

\section{Result}

\subsection{Data Processing Method}

We reviewed the validity of the questions for measuring group cohesion (task, social, perceived, emotional) and group efficacy used in this study as the exploratory and confirmatory factor analysis was conducted to identify common factors and use them as variables. The exploratory factor analysis method used was the varimax method through principle component analysis, and factors with a unique value of 1 or higher were used with factors with a factor load of 0.5 or more. There is no absolute basis for determining factor loading, but a factor of 0.4 or higher was generally considered to be a significant variable and a factor of 0.5 or higher was considered to be an important variable [74].

The exploratory factor analysis was then conducted to determine whether the tools of the variable explain the variable well in theory; the analysis results are as shown in Table 1. In this study, the analysis of measurement models, including the potential variables in the study model, task cohesion, social cohesion, perceived cohesion, emotional cohesion, and group efficacy was validated through Amos 23.0 using the maximum likelihood method. The analysis results showed that the relationships between the variables were all significant; the suitability of the measurement model was also shown as a comparative fit index $(\mathrm{CFI})=0.948$, Tucker-Lewis index $(\mathrm{TLI})=0.941$, the root mean square error of approximation $(\mathrm{RMSEA})=0.070$ (90\% CI: 0.061 0.079), indicating that the measurement model was relatively well-matched in the data. On the other hand, the factor values of the measurement variables that describe the potential variables were all significant at the level of 0.001 .

Table 1. Goodness of fit of the measurement model.

\begin{tabular}{cccccc}
\hline Category & $\chi^{2}$ & df & TLI & CFI & RMSEA (90\% Reliability Level) \\
\hline Measurement Model & 518.457 & 265 & 0.941 & 0.948 & 0.070 \\
\hline
\end{tabular}

\subsection{Hypotheses Testing}

Before the hypothesis test, a correlation analysis was performed using SPSS 22.0 to examine the relationship between each concept of composition (see Table 2). As a result of the analysis, the correlation number between each variable was 0.8 or higher, so the Variance Inflation Factor (VIF) was identified to look at the problem of multicollinearity. The analysis shows that the model can be trusted without multicollinearity, with VIF values for all variables near 1.0.

Correlation analysis shows that all variables have significant positive $(+)$ correlation, except for the relationship between social presence and academic performance, group efficacy and group size, and social presence and group size (Table 2).

Table 2. Means, standard deviations, and correlations.

\begin{tabular}{lllllll}
\hline \multicolumn{1}{c}{ Variables } & Mean & S.D. & $\mathbf{1}$ & $\mathbf{2}$ & $\mathbf{3}$ & $\mathbf{4}$ \\
\hline 1. Group cohesion & 4.25 & 0.52 & & & & \\
\hline 2. Group efficacy & 4.06 & 0.54 & $0.840^{* *}$ & & & \\
\hline 3. Social presence & 3.70 & 0.44 & $0.344^{* *}$ & $0.363^{* *}$ & & \\
\hline 4. Academic performance & 87.89 & 8.80 & $0.300^{* *}$ & $0.205^{* *}$ & 0.024 & \\
\hline 5. Group size & 3.45 & 0.49 & $-0.162^{*}$ & 0.085 & -0.091 & $-0.374^{* *}$ \\
\hline $\mathrm{N}=121 ;$ Significance of correlations: ${ }^{*} p<0.05 ;^{* *} p<0.01$. & & & &
\end{tabular}

Table 3 shows the hypothesis test results. Hypothesis 1 assumed that social presence would be associated with an increased in-group cohesion within a hypothetical learning 
group. The mixed-model test showed a positive relationship between social presence and group cohesion $(\beta=0.332, p<0.001)$, and supports Hypothesis 1 .

Table 3. Results of mixed-model analyses.

\begin{tabular}{|c|c|c|c|c|c|c|c|c|}
\hline \multirow{2}{*}{ Independent Variables } & \multicolumn{2}{|c|}{ Group Cohesion } & \multicolumn{3}{|c|}{ Group Efficacy } & \multicolumn{3}{|c|}{ Academic Performance } \\
\hline & M1 & M2 & M1 & M2 & M3 & M1 & M2 & M3 \\
\hline \multicolumn{9}{|l|}{ Control variables } \\
\hline Group size & $-0.162 *$ & $-0.131 *$ & 0.085 & $0.231^{* * *}$ & $0.255^{* * *}$ & $-0.374^{* *}$ & $-0.338^{* * *}$ & $-0.01^{* *}$ \\
\hline \multicolumn{9}{|l|}{ Direct effect } \\
\hline Social presence & & $0.332^{* * *}$ & & $0.093 * *$ & $-0.639 * *$ & & -0.090 & $-1.253^{* *}$ \\
\hline Group cohesion & & & & $0.845^{* * *}$ & 0.074 & & $0.331^{* * *}$ & -0.899 \\
\hline \multicolumn{9}{|l|}{ Interaction effect } \\
\hline $\begin{array}{l}\text { Social presence } \times \\
\text { Group cohesion }\end{array}$ & & & & & $1.240 * *$ & & & $1.967 *$ \\
\hline
\end{tabular}

$\mathrm{N}=121$; Significance of correlations: ${ }^{*} p<0.05 ;{ }^{* *} p<0.01 ;{ }^{* * *} p<0.001$.

Hypothesis 2 assumed that an interaction effect between social presence and group cohesion exists in group efficacy within the hypothetical learning group. The mixed model test supported the interaction effect $(\beta=1.240, p<0.01)$. Figure 2 shows twoway interactions related to Hypothesis 2. The groups with high and low values of the two variables were classified based on the average values of group cohesion and social presence. The effect on group efficacy was analyzed. Figure 2 clearly illustrates the positive relationship between group cohesion and group efficacy when recognizing high levels of social presence within a virtual learning group.

Hypothesis 3 assumed an interaction effect between social presence and group cohesion in academic performance within the hypothetical learning group. The mixed model test supported the interaction effect $(\beta=1.967, p<0.05)$. Figure 3 shows two-way interactions related to Hypothesis 3 . The group with high and low values for the two variables was classified based on the average values of group cohesion and social presence. The effect on academic performance was analyzed. Figure 3 clearly shows the positive relationship between group cohesion and academic performance when recognizing high levels of social presence within a virtual learning group. In particular, it can be seen that the slope of the function in which group cohesion affects academic performance is steeper than that in groups with lower social presence.

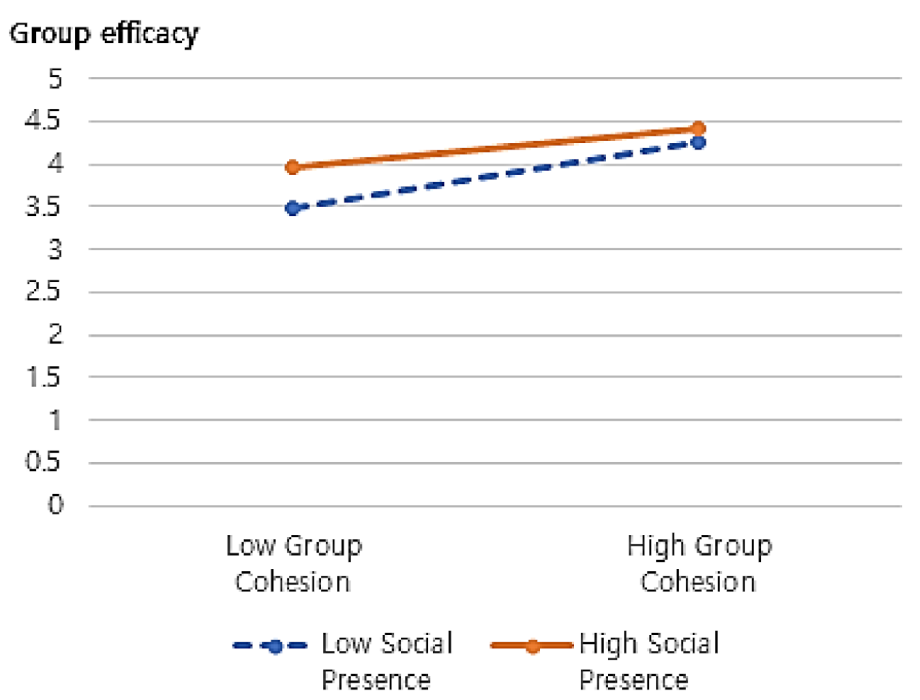

Figure 2. Two-way interaction between group cohesion and group efficacy. 


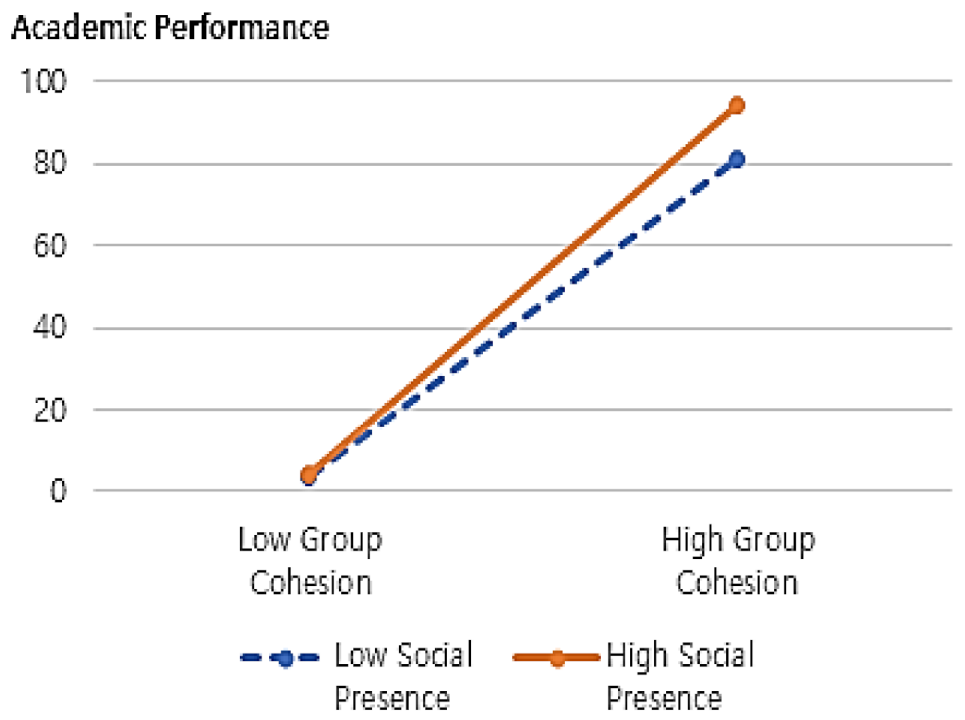

Figure 3. Two-way interaction between group cohesion and academic performance.

\section{Discussion}

More people are using VC as COVID-19 activates social distancing and as technology advances. Accordingly, more attention is needed to explore the relationship between group cohesion and performance in VE such as VC. The purpose of this study was to theoretically explain and empirically investigate the impact of social presence on group cohesion, and to ask how it can affect the efficacy and academic performance of virtual learning groups using VC. This study demonstrated that a high level of social presence has a positive effect on group cohesion and that group cohesion and a sense of social presence have a positive effect on group efficacy and academic performance. Our results emphasize the importance of social presence as a key variable to assist the group's performance in virtual conferences. The results of this study suggest the following:

First, in our group learning using VC, when the group's level of awareness of social presence is high, the group's level of cohesion tends to increase $(\beta=0.332, p<0.001)$. This result confirms the cohesive effect of social presence in the process of VC being used as a tool for human interaction. When examining the implications of the results from an educational point of view, VC has a number of strengths [75,76]: VC tends to be a nonthreatening non-face-to-face environment, yet it has the capacity to allow users to converse face-to-face through the screen. These characteristics result in users perceiving nonverbal communication cues and increase their focus of other group members. In addition, at the group level, group cohesion was promoted by raising participation levels and sharing goals among group members through hard problem-solving tasks [68,69]. It is therefor implied in this study that promoting an awareness of social presence in online learning is both possible and beneficial through video conferencing.

Second, this study hypothesized that group cohesion in VC-based learning has a stronger relationship with group efficacy and academic performance when the level of felt social presence of the members is higher. In this study, the interaction between social presence and group cohesion had a positive effect on group efficacy $(\beta=1.240, p<0.001)$ and on academic performance $(\beta=1.967, p<0.05)$. Our experiment results show that, when participants perceived a greater social presence, the resulting group cohesion and group efficacy enhanced academic performance. In other words, in a virtual learning environment using $\mathrm{VC}$, the learning group members who felt they were actually together also felt that they were more capable than those who did not feel so present in the group. Therefore, we concluded that social presence promotes efficacy. The sense of belonging and intimacy among learners varies depending on the level of awareness of social presence. The social presence felt in the virtual environment makes people more cooperative and motivated to contribute to the group's performance in the same manner as offline in the 
presence of other people. Consequently, with a high level of cohesion, an attitude develops by which they will be able to achieve higher academic performance together. In this study, we show that social presence amplified the effect of group cohesion on group efficacy and on academic performance.

Third, our findings supplement existing findings that state that face-to-face groups develop stronger cohesion than virtual groups. Pearson [77] conducted a study comparing the relationship between cohesion and performance of virtual teams with face-to-face teams. Although face-to-face teams showed stronger cohesion than virtual teams, their learning performance was almost the same. There are two main points that can be added to the discussion by our research results. The first is that face-to-face groups are not alone in offering a sense of cohesion, i.e., it is possible for virtual groups to approximate well to face-to-face groups in achieving cohesion. Well-designed virtual environments and virtual groups can also show strong cohesion depending on the level and effect of social presence. The second relates to the potential for cohesion to be formed in VE. In Pearson's study, there was not much difference between the performance of the virtual team and that of the face-to-face team. Thus, with cohesion formed in a VC-based learning environment, performance may not greatly differ from the results expected in offline groups if social presence is amplified. Therefore, our findings enable us to understand that VE groups can justifiably believe that they can do well and produce equally viable results through enhancing of and experiencing the social presence variable.

Finally, our research extends the existing CSCW/HCI literature on social presence. We found that social presence can combine in VE with variables such as group cohesion to produce significant results, such as group efficacy and academic performance. While there have been many studies on the cohesion of virtual groups in VE, there has been some lack of understanding of how the cohesion of virtual groups can produce results. Our findings highlight the need for CSCW/HCI scholars to pay more attention to how the sense of social presence can be raised in order to promote better results when learning in groups in VE. In addition, due to recently social distancing necessitated by COVID-19, activities such as idea meetings and brainstorming have replaced offline activities through the use of VC. Therefore, we conclude that researchers should explore ways for participants in VE meetings to feel a higher level of social presence, considering the impact of social presence on the outcome of activities using VC.

\subsection{Implications for Design}

As a result of the study, group cohesion on VC was found to have a positive effect on group effectiveness and academic performance. In addition, social presence was confirmed to amplify the positive relationship between group cohesion and academic performance as well as the relationship between group cohesion and group effectiveness. Therefore, in this section, we discuss how to design VC to promote group cohesion and social presence.

First, we presented logical problem-solving activities that required the participation of a number of students in order to increase group cohesion among students on VC. Students had to decide on their individual tasks or roles after discussion to make a collective report on the results of the problem-solving activities. Each student performed individual roles and then reported to the entire group. Individual students in a well cohesive group performed their roles quite faithfully, which in turn led to a large quantity of content for discussion. However, poorly cohesive groups did not show this. Therefore, we propose a function to reflect on groups and individuals as a function of VC to aid group cohesion. This function will evaluate individual contributions to the group in a self-reporting manner, with the group's academic performance evaluated anonymously by individuals. The purpose of the evaluation is to enhance the level of participation and cooperative skills of group members by emphasizing the cohesiveness of the group. In addition, a method of selecting and rewarding individuals who have performed excellent activities within the group may be introduced to induce interest in the evaluation itself. For example, at the beginning of group activities, each individual is given a certain number of points, 
which can only be used for compensation as a result of evaluation of group members. The final aggregated points can also be reflected into individual performance to induce goodwill competition among group members. This approach is based on a group exploration model $[78,79]$ in which the achievement of a group's task is the source of cohesion, and on a group activity's motivational view [80] that the introduction of a reward system facilitates collaborative interaction.

Second, we propose to add a function that enables participants to actively express their emotions in order to enhance social presence on VC. The level of social presence online varies depending on the psychological distance between the participants $[23,49,54]$. Thus, as a function to enhance social presence, a messaging function designed to reveal individual closeness to members can be introduced to VC. This emotion expression function enables members who have become close while introducing themselves at the beginning of the group or performing tasks to ask each other how they are doing and form a close atmosphere between them. In addition, it may be considered to introduce functions designed to more actively facilitate social support. Social support functions serve to manage the group's emotional atmosphere during online cooperative activities on VC, and may be composed of group management functions, cooperation promotion functions, and conflict management functions. First, group management functions are designed to facilitate the operation of groups to perform tasks for group activities. Specifically, such activities include naming the group, creating rules for the group, and coordinating the group's schedules and distributing roles. An example of cooperation promotion functions is sending text messages or emoticons that have a positive impact on facilitating group collaboration in the course of performing tasks. Specific types are motivating members, requesting participation, praising group collaboration, and increasing confidence in performing tasks. First, motivating members refers to member messages motivating others to participate earnestly on their own. Next, requesting participation refers to messages to encourage members to participate more actively. This type of message refers to a message that asks for feedback on the results of the task or requests a follow-up task to members who are negligent or unresponsive. In addition, a message praising group collaboration can be used as a way to express affection and affinity for the group and to increase group cohesion. Finally, as they gain confidence or have more clarity about successful task performance, it is expected that messages that can provide feedback to each other will also help improve intimacy and efficacy among participants.

Third, in this study, group efficacy influenced academic performance in combination with social presence. However, groups whose members showed negligence would in turn display declined group dynamics and record poor academic performance. Conflict management functions, such as those that are conflict-causing, allow giving feedback while exchanging messages related to factors that can negatively affect cooperation when carrying out cooperative tasks. Specific types are mainly related to fallen motivation, delayed submission of task results by members, unclear job division, conflicting schedules, and social loafing (such as absence during group activities, etc.). To prevent or reduce these negligence-related issues, one can consider adding functions such as alerting schedules on the system and sending proactive notifications, group leaders sending messages (or emails) and other members sending supporting messages. A system that automatically deducts points and reflects it in academic performance if members fail to submit assignments on time or provide feedback to other members can also be considered. In summary, this study has significant implications for designing collaborative systems on VC. Ultimately, how to promote group cohesion and social presence on $\mathrm{VC}$ will depend on the purpose and the nature of activities to be performed on VC. Our findings are expected to help $\mathrm{CSCW} / \mathrm{HCI}$-related researchers design VC-based collaborative systems.

\subsection{Limitations}

This study has a limitation in that all of its research subjects were female. Since gender has been found to be an individual-level factor affecting the efficacy of web-based virtual 
learning [81], subsequent studies require more in-depth research into non-face-to-face learning environments to reveal gender-based online learning outcomes by selecting a gender balance among research subjects. In addition, in future studies, not only gender but also differences due to age or cultural background need to be studied. Future research calls for attempts to shed more light on the relationship to online learning situations using virtual applications in various fields and disciplines. In particular, it is argued that the non-face-to-face environment in $\mathrm{VC}$ reduces the frequency of social interactions compared to face-to-face learning environments [82]. Thus, various strategies and ways to facilitate interactive communication between learners in online learning using VC need to be explored in future research.

\section{Conclusions}

Through this study, it was suggested that social presence in VC can have a positive effect on group efficacy and performance by amplifying group cohesion. Some previous studies have shown that the trust and aggregation of members in a virtual environment drives the group's performance, while specific suggestions on how to create trust and aggregation have been lacking $[83,84]$, although learners tend to be more satisfied with group activity when they have a higher social connection in VE [85]. Our research results suggest that group activities using VC can create similar effects on group activities in offline face-to-face activities. Online learning environments using VC, which do not have the advantages of offline face-to-face interaction and social interactions between students, can be tuned to achieve similar experiences and results. Above all, performing difficult tasks using VC makes group members more cohesive, and active interaction increases social presence $[68,69]$. At a time when home-based learning and homework are increasing due to COVID-19 related restrictions, concerns about the inability to study and work offline in groups can be resolved by increasing the effect of social presence in VC. In particular, our experimental results show that in $\mathrm{VC}$, the creation of a sense of social presence promotes group cohesion, and groups with a strong level of group cohesion show higher levels of group efficacy and academic performance. These research results show that system designers can include features that help participants create a sense of social presence, group cohesion, and group efficacy in VC and thereby facilitate higher academic performance even though they may not have face-to-face interaction in the offline world. This study collected data by researching it on a semester basis so that students could create more opportunities to contact and meet in general VC utilization situations. Our results show that there is a positive correlation between physical time and group activity in VC. Therefore, in VC-based activities, it is necessary to select an application that can support group activities and secure time for interaction among participants to promote social presence. This study also emphasizes the importance of introducing functions that support task recognition and social interaction as a way to increase social presence and group cohesion in VC. Specifically, social support that is intrinsically provided in well-designed VC will help build group cohesion. Finally, this study presents prospects for online activities using VC to complement face-to-face learning. The recent COVID-19 crisis forces us to reshape and divert major sections of daily life such as work and study into online activities. Pandemic conditions make it necessary to prepare for non-face-to-face work and education environments and to find ways to effectively utilize VC. This study is significant in that we examined the theoretical model for group learning through experimentation and suggested ways to promote group performance by enhancing group cohesion and social presence.

Author Contributions: The authors contributed equally to this work. All authors have read and agreed to the published version of the manuscript.

Funding: This research received no external funding.

Institutional Review Board Statement: Ethical review and approval were waived for this study because although it was a human study, it was observational, and the research design did not involve ethical issues. 
Informed Consent Statement: Informed consent was obtained from all subjects involved in the study.

Data Availability Statement: Not applicable.

Conflicts of Interest: The authors declare no conflict of interest.

\section{Appendix A Questionnaire}

\begin{tabular}{|c|c|c|}
\hline \multirow{7}{*}{ Task Cohesion } & 1 & I wish to see our study group get excellent scores. \\
\hline & 2 & Our study group gives me ample opportunities to improve my learning outcomes. \\
\hline & 3 & I like the way our study group solves problems and shares answers. \\
\hline & 4 & Our study group strives to increase scores for solving exercises after the professor's ZOOM LIVE class. \\
\hline & 5 & Our study group has a desire to increase our scores for practice problems. \\
\hline & 6 & If one of our study group members is having a problem, all other team members will try to help. \\
\hline & 7 & Members of our study group freely communicate their roles and responsibilities during problem solving activities. \\
\hline \multirow{6}{*}{ Social Cohesion } & 1 & I like to participate in non-learning activities in our study group (e.g. sharing personal affairs, meeting offline). \\
\hline & 2 & My best friend might be one of the people in our study group. \\
\hline & 3 & I think I will enjoy other meetings more than our group meetings after the offline class starts. \\
\hline & 4 & (R) Our study team members prefer to solve problems on their own rather than as a group. \\
\hline & 5 & Our study group members have a desire to spend time together outside of problem solving time. \\
\hline & 6 & When our study group members start meeting offline, they will stick together outside of problem solving time. \\
\hline \multirow{6}{*}{ Perceived Cohesion } & 1 & I feel that I belong to this study group. \\
\hline & 2 & I am pleased to be part of this study group. \\
\hline & 3 & I consider myself a part of this study group. \\
\hline & 4 & I think our study group is the best. \\
\hline & 5 & I think I am part of this study group. \\
\hline & 6 & I am happy to participate in this study group. \\
\hline \multirow{4}{*}{$\begin{array}{l}\text { Emotional } \\
\text { Cohesion }\end{array}$} & 1 & This study group has tremendous energy. \\
\hline & 2 & This study group has a team spirit. \\
\hline & 3 & I am excited just to have this study group. \\
\hline & 4 & I am happy when I participate in this group activity. \\
\hline \multirow{7}{*}{ Group Efficacy } & 1 & Our study group has excellent abilities. \\
\hline & 2 & Our study group does no worse at solving problems than other study groups. \\
\hline & 3 & Our study group performs well enough to achieve its necessary goals. \\
\hline & 4 & Members of our study group have excellent problem solving skills. \\
\hline & 5 & Some of our study group members are very talented. \\
\hline & 6 & Our study group solves problems very efficiently. \\
\hline & 7 & Members of our study group do their jobs. \\
\hline
\end{tabular}




\begin{tabular}{|c|c|c|}
\hline \multirow{11}{*}{ Social Presence } & 1 & In class, the students seem to know of my existence. \\
\hline & 2 & I feel like learning with the students in class. \\
\hline & 3 & In class, students are interested in what I do. \\
\hline & 4 & It seems that the students in class have a high interest in each other. \\
\hline & 5 & In class, students accept each others' opinions well. \\
\hline & 6 & Students exchange help with each other. \\
\hline & 7 & It is fun to share opinions with the students. \\
\hline & 8 & Immediate responses to my opinions are offered. \\
\hline & 9 & I feel comfortable talking to the students and exchanging opinions. \\
\hline & 10 & My ideas help with teamwork. \\
\hline & 11 & I feel close to the students. \\
\hline
\end{tabular}

\section{References}

1. Faste, H.; Rachmel, N.; Essary, R.; Sheehan, E. Brainstorm, Chainstorm, Cheatstorm, Tweetstorm: New ideation strategies for distributed HCI design. In Proceedings of the SIGCHI Conference on Human Factors in Computing Systems, Paris, France, 27 April-2 May 2013; pp. 1343-1352.

2. Chan, J.; Dang, S.; Dow, S.P. Improving Crowd Innovation with Expert Facilitation. In Proceedings of the 19th ACM Conference on Computer-Supported Cooperative Work \& Social Computing, San Francisco, CA, USA, 27 February-2 March 2016; pp. 1223-1235.

3. Yu, L.; Kittur, A.; Kraut, R.E. Encouraging "Outside- the- box" Thinking in Crowd Innovation Through Identifying Domains of Expertise. In Proceedings of the 19th ACM Conference on Computer-Supported Cooperative Work \& Social Computing, San Francisco, CA, USA, 27 February-2 March 2016; pp. 1214-1222.

4. Golembewski, M.; Selby, M. Ideation decks: A card-based design ideation tool. In Proceedings of the 8th ACM Conference on Designing Interactive Systems, Aarhus, Denmark, 16-20 August 2010; pp. 89-92.

5. Sowden, P.T.; Dawson, L. Creative feelings: The effect of mood on creative ideation and evaluation. In Proceedings of the 8th ACM conference on Creativity and cognition, Atlanta, GA, USA, 3-6 November 2011; pp. 393-394.

6. Sosa, R.; Dong, A. The creative assessment of rich ideas. In Proceedings of the 9th ACM Conference on Creativity \& Cognition, Sydney, NSW, Australia, 17-20 June 2013; pp. 328-331.

7. Anggrawan, A.; Jihadil, Q.S. Comparative Analysis of Online E-Learning and Face To Face Learning: An Experimental Study. In Proceedings of the 2018 Third International Conference on Informatics and Computing (ICIC), Palembang, Indonesia, 17-18 October 2018; pp. 1-4.

8. Roberts, T.S.; McInnerney, J.M.; Society. Seven problems of online group learning (and their solutions). J. Educ. Technol. 2007, 10, 257-268.

9. James, B.; Poonam, K. Students' Perceptions of Teaching and Social Presence: A Comparative Analysis of Face-to-Face and Online Learning Environments. Int. J. Web Based Learn. Teach. Technol. (IJWLTT) 2015, 10, 27-44. [CrossRef]

10. Khan, M.A.; Nabi, M.K.; Khojah, M.; Tahir, M. Students' Perception towards E-Learning during COVID-19 Pandemic in India: An Empirical Study. Sustainability 2021, 13, 57. [CrossRef]

11. Nortvig, A.-M.; Petersen, A.K.; Balle, S.H. A Literature Review of the Factors Influencing E-Learning and Blended Learning in Relation to Learning Outcome, Student Satisfaction and Engagement. Electron. J. e Learn. 2018, 16, 46-55.

12. Alqahtani, A.Y.; Rajkhan, A.A. E-learning critical success factors during the covid-19 pandemic: A comprehensive analysis of e-learning managerial perspectives. Educ. Sci. 2020, 10, 216. [CrossRef]

13. Azmitia, M. Peer interaction and problem solving: When are two heads better than one? J. Child. Dev. 1988, 87-96. [CrossRef]

14. Dembo, M.H.; McAuliffe, T. Effects of perceived ability and grade status on social interaction and influence in cooperative groups. J. Educ. Psychol. 1987, 79, 415-423. [CrossRef]

15. Hooper, S.; Hannafin, M. Cooperative CBI: The effects of heterogeneous versus homogeneous grouping on the learning of progressively complex concepts. J. Educ. Comput. Res. 1988, 4, 413-424. [CrossRef]

16. Al-Abri, A.; Jamoussi, Y.; Kraiem, N.; Al-Khanjari, Z. Comprehensive classification of collaboration approaches in E-learning. Telemat. Inform. 2017, 34, 878-893. [CrossRef]

17. Khan, A.; Egbue, O.; Palkie, B.; Madden, J. Active learning: Engaging students to maximize learning in an online course. Electron. J. E Learn. 2017, 15, 107-115.

18. Misa, C.; Guse, D.; Hohlfeld, O.; Durairajan, R.; Sperotto, A.; Dainotti, A.; Rejaie, R. Lessons learned organizing the PAM 2020 virtual conference. ACM SIGCOMM Comput. Commun. Rev. 2020, 50, 46-54. [CrossRef]

19. Pal, D.; Vanijja, V.; Patra, S. Online Learning During COVID-19: Students' Perception of Multimedia Quality. In Proceedings of the 11th International Conference on Advances in Information Technology, Bangkok, Thailand, 1-3 July 2020 ; p. 27. 
20. Le, D.A.; Maclntyre, B.; Outlaw, J. Enhancing the Experience of Virtual Conferences in Social Virtual Environments. In Proceedings of the 2020 IEEE Conference on Virtual Reality and 3D User Interfaces Abstracts and Workshops (VRW), Atlanta, GA, USA, 22-26 March 2020; pp. 485-494.

21. Lee, M.; Bruder, G.; Welch, G.F. Exploring the effect of vibrotactile feedback through the floor on social presence in an immersive virtual environment. In Proceedings of the 2017 IEEE Virtual Reality (VR), Los Angeles, CA, USA, 18-22 March 2017; pp. 105-111.

22. Srivastava, S.C.; Chandra, S. Social presence in virtual world collaboration: An uncertainty reduction perspective using a mixed methods approach. MIS Q. 2018, 42, 779-804. [CrossRef]

23. Garrison, D.R. Online community of inquiry review: Social, cognitive, and teaching presence issues. J. Asynchronous Learn. Netw. 2007, 11, 61-72. [CrossRef]

24. Parameswaran, S. Social Presence in Social Media: Persuasion, Design and Discourse. In Proceedings of the 2017 ACM SIGMIS Conference on Computers and People Research, Bangalore, India, 21-23 June 2017; pp. 205-206.

25. Goda, Y.; Yamada, M. Visualization of Social and Cognitive Presences for Collaborative Learning Facilitation. In Proceedings of the Society for Information Technology \& Teacher Education International Conference 2019, Las Vegas, NV, USA, 18-22 March 2019; pp. 1020-1024.

26. So, H.-J.; Brush, T.A. Student perceptions of collaborative learning, social presence and satisfaction in a blended learning environment: Relationships and critical factors. Comput. Educ. 2008, 51, 318-336. [CrossRef]

27. Richardson, J.C.; Maeda, Y.; Lv, J.; Caskurlu, S. Social presence in relation to students' satisfaction and learning in the online environment: A meta-analysis. Comput. Hum. Behav. 2017, 71, 402-417. [CrossRef]

28. Law, E.L.-C.; van Schaik, P.; Roto, V. Attitudes towards user experience (UX) measurement. Int. J. Hum. Comput. Stud. 2014, 72, 526-541. [CrossRef]

29. Forsyth, D.R. Group Dynamics; Cengage Learning: Boston, MA, USA, 2018.

30. Gouardères, E.; Gouardères, G. Enhancing Group Cohesion in Virtual Communities of Practice. In Proceedings of the 2011 IEEE/WIC/ACM International Conferences on Web Intelligence and Intelligent Agent Technology, Lyon, France, 22-27 August 2011; pp. 318-321.

31. Harun, M.Z.M.; Chin, O. Examining the association between group cohesion and group performance in the co-operative movement. Int. J. Bus. 2015, 1, 26-30.

32. Mullen, B.; Copper, C. The relation between group cohesiveness and performance: An integration. J. Psychol. Bull. 1994, 115, 210-227. [CrossRef]

33. Tekleab, A.G.; Quigley, N.R.; Tesluk, P.E. A Longitudinal Study of Team Conflict, Conflict Management, Cohesion, and Team Effectiveness. Group Organ. Manag. 2009, 34, 170-205. [CrossRef]

34. Suh, H.-J.; Lee, S.-W. Collaborative Learning Agent for Promoting Group Interaction. ETRI J. 2006, 28, 461-474. [CrossRef]

35. Arquilla, J.; Guzdial, M. Transitioning to distance learning and virtual conferencing. Commun. ACM 2020, 63, 10-11. [CrossRef]

36. Torres Martín, C.; Acal, C.; El Honrani, M.; Mingorance Estrada, Á.C. Impact on the Virtual Learning Environment Due to COVID-19. Sustainability 2021, 13, 582. [CrossRef]

37. Bandura, A. Self-efficacy mechanism in human agency. J. Am. Psychol. 1982, 37, 122-147. [CrossRef]

38. Bandura, A. Self-Self Efficacy: The Exercise of Control; Freeman: New York, NY, USA, 1997.

39. Lent, R.W.; Sheu, H.-B.; Singley, D.; Schmidt, J.A.; Schmidt, L.C.; Gloster, C.S. Longitudinal relations of self-efficacy to outcome expectations, interests, and major choice goals in engineering students. J. Vocat. Behav. 2008, 73, 328-335. [CrossRef]

40. Walther, J.B. Interpersonal Effects in Computer-Mediated Interaction: A Relational Perspective. Commun. Res. 1992, 19, 52-90. [CrossRef]

41. Wilson, J.M.; Straus, S.G.; McEvily, B. All in due time: The development of trust in computer-mediated and face-to-face teams. Organ. Behav. Hum. Decis. Process. 2006, 99, 16-33. [CrossRef]

42. Bandura, A. The Explanatory and Predictive Scope of Self-Efficacy Theory. J. Soc. Clin. Psychol. 1986, 4, 359-373. [CrossRef]

43. Zaccaro, S.; Blair, V.; Peterson, C.; Zazanis, M. Collective Efficacy. In Self Efficacy, Adaptation, and Adjustment: Theory, Research, and Application; Maddux, J.E., Ed.; Plenum Press: New York, NY, USA, 1995.

44. Gully, S.M.; Incalcaterra, K.A.; Joshi, A.; Beaubien, J.M. A meta-analysis of team-efficacy, potency, and performance: Interdependence and level of analysis as moderators of observed relationships. J. Appl. Psychol. 2002, 87, 819-832. [CrossRef]

45. Khong, J.Z.N.; Liem, G.A.D.; Klassen, R.M. Task performance in small group settings: The role of group members' self-efficacy and collective efficacy and group's characteristics. Educ. Psychol. 2017, 37, 1082-1105. [CrossRef]

46. Watson, C.B.; Chemers, M.M.; Preiser, N. Collective Efficacy: A Multilevel Analysis. Personal. Soc. Psychol. Bull. 2001, 27, 1057-1068. [CrossRef]

47. Yontz, E. Enriching Social Presence through Research and Practice: A Review of "Social Presence in Online Learning". eLearn Mag. 2018, 2018, 2. [CrossRef]

48. Yasir, A.; Hu, X.; Ahmad, M.; Rauf, A.; Shi, J.; Ali Nasir, S. Modeling impact of word of mouth and E-government on online social presence during COVID-19 Outbreak: A multi-mediation approach. Int. J. Environ. Res. Public Health 2020, 17, 2954. [CrossRef]

49. Toader, D.-C.; Boca, G.; Toader, R.; Măcelaru, M.; Toader, C.; Ighian, D.; Rădulescu, A.T. The effect of social presence and chatbot errors on trust. Sustainability 2020, 12, 256. [CrossRef]

50. Pereira, A.; Prada, R.; Paiva, A. Improving social presence in human-agent interaction. In Proceedings of the SIGCHI Conference on Human Factors in Computing Systems, Toronto, ON, Canada, 14 April-26 May 2014; pp. 1449-1458. 
51. Short, J.; Williams, E.; Christie, B. The Social Psychology of Telecommunications; John Wiley \& Sons: Hoboken, NJ, USA, 1976.

52. Swan, K. Developing Social Presence in Online Course Discussions. In Learning $\mathcal{E}$ Teaching with Technologies, Principles and Practices; Routledge: Sterling, VA, USA; London, UK, 2003; pp. 147-164.

53. Swan, K.; Shih, L.F. On the nature and development of social presence in online course discussions. J. Asynchronous Learn. Netw. 2005, 9, 115-136. [CrossRef]

54. Garrison, D.R.; Anderson, T.; Archer, W. Critical thinking, cognitive presence, and computer conferencing in distance education. Am. J. Distance Educ. 2001, 15, 7-23. [CrossRef]

55. Garrison, D.R.; Arbaugh, J.B. Researching the community of inquiry framework: Review, issues, and future directions. Internet High. Educ. 2007, 10, 157-172. [CrossRef]

56. Hayashi, A.; Chen, C.; Ryan, T.; Wu, J. The role of social presence and moderating role of computer self efficacy in predicting the continuance usage of e-learning systems. J. Inf. Syst. Educ. 2020, 15, 139-154.

57. Rifkind, L.J. Immediacy as a predictor of teacher effectiveness in the instructional television. J. Interact. Telev. 1992, 1, 31-38.

58. Rogers, P.; Lea, M. Social presence in distributed group environments: The role of social identity. Behav. Inf. Technol. 2005, 24, 151-158. [CrossRef]

59. Widén-Wulff, G.; Ginman, M. Explaining knowledge sharing in organizations through the dimensions of social capital. J. Inf. Sci. 2004, 30, 448-458. [CrossRef]

60. Stajkovic, A.D.; Lee, D.; Nyberg, A. Collective efficacy, group potency, and group performance: Meta-analyses of their relationships, and test of a mediation model. J. Appl. Psychol. 2009, 94, 814-828. [CrossRef]

61. George, J.M. Leader positive mood and group performance: The case of customer service. J. Appl. Soc. Psychol. 1995, 25, 778-794. [CrossRef]

62. Riggs, M.L.; Knight, P.A. The impact of perceived group success-failure on motivational beliefs and attitudes: A causal model. J. Appl. Psychol. 1994, 79, 755. [CrossRef]

63. Lee, Y. Collective Efficacy and Self-Directed Learning Ability on Learning Satisfaction among Study-Group Participating Public Officials. Ph.D. Thesis, Soongsil University, Seoul, Korea, 2011, unpublished.

64. Aragon, S.R. Creating social presence in online environments. New Dir. Adult Contin. Educ. 2003, 2003, 57-68. [CrossRef]

65. Charlton, T.; Marshall, L.; Devlin, M. Evaluating the extent to which sociability and social presence affects learning performance. In Proceedings of the 13th annual conference on Innovation and technology in computer science education, Madrid, Spain, 11-13 June 2014; p. 342.

66. Hill, N.S.; Offermann, L.R.; Thomas, K. Mitigating the detrimental impact of maximum negative affect on team cohesion and performance through face-to-face communication. Group Organ. Manag. 2019, 44, 211-238. [CrossRef]

67. Podsakoff, P.M.; MacKenzie, S.B.; Lee, J.Y.; Podsakoff, N.P. Common method biases in behavioral research: A critical review of the literature and recommended remedies. J. Appl. Psychol. 2003, 88, 879-903. [CrossRef]

68. Poltrock, S.E.; Engelbeck, G. Requirements for a virtual collocation environment. In Proceedings of the international ACM SIGGROUP conference on Supporting group work: The integration challenge, Phoenix, AZ, USA, 16-19 November 1997; pp. 61-70.

69. Mark, G.; Grudin, J.; Poltrock, S.E. Meeting at the desktop: An empirical study of virtually collocated teams. In Proceedings of the ECSCW'99, Copenhagen, Denmark, 12-16 September 1999; pp. 159-178.

70. Lomicka, L.; Lord, G. Social presence in virtual communities of foreign language (FL) teachers. System 2007, 35, 208-228. [CrossRef]

71. Kang, M.J.; Kim, J.; Park, M. Investigating presence as a predictor of learning outcomes in e-learning environment. In Proceedings of the EdMedia+ Innovate Learning, Vienna, Austria, 30 June 2008; pp. 4175-4180.

72. Wang, E.T.G.; Ying, T.-C.; Jiang, J.J.; Klein, G. Group cohesion in organizational innovation: An empirical examination of ERP implementation. Inf. Softw. Technol. 2006, 48, 235-244. [CrossRef]

73. Siebold, G.L. Society. The essence of military group cohesion. Armed Forces 2007, 33, 286-295. [CrossRef]

74. Suh il, C. Social Science Research Methodology, 3rd ed.; B\&M Books: Seoul, Korea, 2007.

75. Themelis, C.; Sime, J.-A. From Video-Conferencing to Holoportation and Haptics: How Emerging Technologies Can Enhance Presence in Online Education? In Emerging Technology and Pedagogies in the Curriculum; Springer: Berlin/Heidelberg, Germany, 2020; pp. 261-276.

76. Nguyen, D.T.; Canny, J. Multiview: Improving trust in group video conferencing through spatial faithfulness. In Proceedings of the SIGCHI conference on Human factors in computing systems, San Jose, CA, USA, April 28-May 3 2007; pp. 1465-1474.

77. Pearson, J. Investigating ICT using problem-based learning in face-to-face and online learning environments. Comput. Educ. 2006, 47, 56-73. [CrossRef] [PubMed]

78. Johnson, D.W. Cooperative Learning in the Classroom; ERIC; Association for Supervision and Curriculum Development: Alexandria, VA, USA, 1994.

79. Jolliffe, W. Cooperative Learning in the Classroom: Putting it into Practice; Sage: Thousand Oaks, CA, USA, 2007.

80. Dayan, P.; Balleine, B.W. Reward, motivation, and reinforcement learning. Neuron 2002, 36, 285-298. [CrossRef]

81. Chung, K.-S.; Park, Y.-J. Factors Influencing the Effectiveness of the Wed-based Virtual Learning. Korean Bus. Educ. Rev. 2004, 35, 35-59.

82. Rourke, L. Operationalizing social interaction in computer conferencing. In Proceedings of the 16th Annual conference of the Canadian Association for Distance Education, Quebec City, Canada, 3-6 May 2000; pp. 335-353. 
83. Paul, R.; Drake, J.R.; Liang, H. Global virtual team performance: The effect of coordination effectiveness, trust, and team cohesion. IEEE Trans. Prof. Commun. 2016, 59, 186-202. [CrossRef]

84. Furumo, K.; Pearson, J.M. An empirical investigation of how trust, cohesion, and performance vary in virtual and face-to-face teams. In Proceedings of the 39th Annual Hawaii International Conference on System Sciences (HICSS’06), Kauai, HI, USA, 4-7 January 2006; p. 26c.

85. Bulu, S.T. Place presence, social presence, co-presence, and satisfaction in virtual worlds. Comput. Educ. 2012, 58, 154-161. [CrossRef] 